\title{
Percepção da palatalização do /S/ em coda: atitudes linguísticas de universitários
}

\section{Perception of the palatalization of the /S/ in coda: linguistic attitudes of university students}

\author{
Josilene de Jesus Mendonça ${ }^{1}$ \\ Cósmia Karine Vieira Borges ${ }^{2}$
}

Resumo: O comportamento linguístico pode ser descrito e compreendido a partir dos julgamentos que os falantes fazem sobre determinado fenômeno linguístico. O falante exerce, de forma mais ou menos consciente, avaliações positivas ou negativas em relação a fenômenos variáveis da língua, influenciando o direcionamento dos processos de variação e mudança linguísticas (LABOV, 2008). Partindo dessa premissa, objetivamos analisar a percepção e a avaliação de universitários da Universidade Federal de Sergipe, Campus Prof. Alberto Carvalho, em relação à palatalização do /S/ em coda silábica. Para realizarmos este estudo, adotando uma abordagem direta, utilizamos um teste de atitudes linguísticas com perguntas relacionadas à palatalização do /S/ em coda, considerando o contexto seguinte $t$, com os estímulos pasta, costa, pista, e o contexto de coda externa, com os estímulos lápis, ônibus, depois. A partir dos pressupostos da Sociolinguística Variacionista (LABOV, 2008), aplicamos um questionário a 60 informantes. Os resultados evidenciam que os universitários apresentam avaliação neutra em relação à palatalização do /S/ em coda no contexto seguinte t. Por outro lado, a palatalização no contexto de coda externa é alvo de avaliação negativa. Esses resultados evidenciam que a percepção dos universitários em relação à palatalização é sensível ao contexto linguístico.

Palavras-chave: Palatalização do /S/; Variação; Percepção.

Abstract: The linguistic behavior can be described and understood based on judgments speakers do about certain linguistic phenomena. The speaker execute, in kind of a conscientious way, positive and negative interpretations in relation to language variants phenomena, influencing the process of variation and linguistic change (LABOV, 2008). Assuming that premise, we intended to analyze the perception and perception of the students of Universidade Federal de Sergipe, Campus Prof. Alberto Carvalho, in relation to the palatalization of the /S/ in syllabic coda. In order to conduct the study, adopting a direct approach, we used an attitude linguistic test with questions related to the palatalization of /S/ in coda, considering the context of the following $t$, with the stimulus pasta, costa pista, and the context of external coda, and the stimulus lápis, ônibus, depois. From the assumptions of the variationist sociolinguistics (LABOV, 2008), we applied a questionnaire to 60 informants. The results highlighted that the university students showed a neutral perception in relation to the palatalization of the $/ S /$ in coda in the context of the following $t$. In the other hand, the palatalization in the context of external coda is target of negative perception. These results evidence that the perception of the university students in relation to palatalization is sensitive to the linguistic context.

Keywords: Palatalization of /S/; Variation; Perception.

\footnotetext{
${ }^{1}$ Doutoranda pelo Programa de Pós-Graduação em Letras da Universidade Federal de Sergipe. E-mail: mendoncajosilene@gmail.com.

${ }^{2}$ Graduanda em Letras Português pela Universidade Federal de Sergipe - Campus Prof. Alberto Carvalho. Participa do Programa de Iniciação Científica Voluntária - PICVOL. E-mail: karinevieiraborges@hotmail.com.
} 


\section{Introdução}

A língua possui um sistema variável e dinâmico (WEINREICH; LABOV; HERZOG, 2006). Por mais que compartilhemos de uma mesma língua ou variedade linguística, não nos expressamos da mesma forma, pois a linguagem é um fator social (FARACO, 2012). Embora os indivíduos relacionem-se e comuniquem-se entre si, todos eles possuem maneiras diferentes de falar, dependendo da situação em que estejam, formal ou informal, da sua origem, da escolaridade, da classe social, dentre outros fatores sociais (ALKMIM, 2001).

O comportamento linguístico pode ser descrito e compreendido a partir dos julgamentos que os falantes fazem sobre determinado fenômeno linguístico. O falante exerce, de forma mais ou menos consciente, avaliações positivas ou negativas em relação a fenômenos variáveis da língua, influenciando o direcionamento dos processos de variação e mudança linguísticas (LABOV, 2008). Segundo Oushiro (2015, p. 32), o termo avaliação "é empregado para fazer referência ao discurso metalinguístico dos falantes sobre variantes". Em outras palavras, o falante atribui julgamentos valorativos às variantes linguísticas de acordo com a sua percepção em relação ao fenômeno linguístico, considerando fatores de ordem social como escolaridade e região, por exemplo. Estudar as percepções e as avaliações dos falantes em relação a determinado fenômeno linguístico é, portanto, uma forma de compreender o comportamento linguístico de uma comunidade. Nessa perspectiva, objetivamos analisar a percepção e a avaliação de universitários da Universidade Federal de Sergipe, Campus Prof. Alberto Carvalho, em relação à palatalização do /S/ em coda silábica.

$\mathrm{O}$ /S/ em coda pode ser realizado fonologicamente de forma alveolar ou palatal, podendo apresentar-se de maneira vozeada [z, 3] ou desvozeada [s, $\left.\int\right]$ (SILVA, 2003). Quando o contexto seguinte é uma consoante vozeada, o /S/ em coda também é vozeado, por exemplo, deZde (alveolar) e dezde (palatal). Diante de uma consoante desvozeada, há a realização desvozeada do /S/, por exemplo, em paSta (realização alveolar) e pasta (realização palatal).

Para analisarmos as atitudes linguísticas dos universitários em relação à palatalização do /S/ em coda, considerando os pressupostos da Sociolinguística Variacionista (LABOV, 2008), aplicamos um questionário de atitudes linguísticas a 60 universitários. O questionário, elaborado a partir de uma abordagem direta das atitudes, contém perguntas de julgamento metalinguístico relacionadas a estímulos com a realização palatal do /S/ em coda, conforme descrito nos procedimentos metodológicos.

Na seção a seguir, discutimos noções relacionadas à avaliação social das variedades linguísticas. Em seguida, apresentamos os procedimentos metodológicos. Depois, expomos e discutimos a avaliação dos universitários em relação à palatalização do /S/ em coda, considerando a percepção do fenômeno, as crenças relativas ao uso linguístico, o julgamento metalinguístico e a percepção do fator regional, da escolaridade e do preconceito linguístico como fatores sociais relacionadas à realização palatal do /S/ em coda. Em seguida, apresentamos as considerações finais, tecendo conclusões a respeito da percepção de universitários em relação à palatalização do /S/. 


\section{Avaliação social das variedades linguísticas}

As relações sociais estabelecidas em uma comunidade atuam nos processos de variação e mudança linguísticas, consequentemente, também se relacionam com os julgamentos valorativos que os falantes fazem, com maior ou menor grau de consciência, das variedades linguísticas. Os fenômenos variáveis da língua recebem valorações sociais diferentes, pois, por mais que as variantes linguísticas apresentem o mesmo valor de verdade ou representacional, as pressões sociais operam constantemente sobre a língua (FREITAG et al., 2016). Essas avaliações diferentes são atribuídas, não por essas formas linguísticas serem distintas entre si, mas pela forma como são vistas socialmente, pois as formas em variação podem adquirir valores, em função, por exemplo, do poder e da autoridade que os falantes possuem nas relações econômicas e culturais (CAMACHO, 2001).

As diferentes variedades linguísticas existentes apresentam prestígio ou estigma na sociedade; isso acontece porque há uma ordenação valorativa dessas variedades linguísticas quanto ao seu uso, o que acaba refletindo numa hierarquia dos grupos sociais. Segundo Alkmim (2001), em todas as comunidades, existem variedades que são consideradas superiores e inferiores. Quando uma variedade linguística de determinado indivíduo é avaliada, não é somente o seu uso linguístico que vai ser julgado, mas também o próprio indivíduo. A sociedade considera apenas uma variedade como correta, a variedade culta, utilizada por grupos sociais com poder e prestígio socioeconômico. Essa variedade culta é a variedade linguística mais valorizada socialmente, requerida nas situações mais formais, a que é pregada nos meios midiáticos e nas instituições. Quando não há aceitação das diferenças, surge espaço para o preconceito social e linguístico.

Essa variedade culta, considerada pela sociedade como única, pertence aos grupos socialmente dominantes, as classes sociais altas de determinadas regiões geográficas. Há uma atitude social conservadora em relação à língua, prezando por um modo de falar entre vários outros existentes na comunidade, considerando esse único modo de falar como o "correto". Com base em um ideal de língua homogênea, essa avaliação social exclui as outras variedades linguísticas, considerando-as "inferiores", "erradas" ou "simples", não levando em conta a realidade da variação linguística, a diversidade social e cultural existentes.

A avaliação social de fenômenos linguísticos depende do nível de consciência em relação às formas linguísticas que a comunidade compartilha. Labov (2008) propõe uma classificação dos fenômenos variáveis em indicadores, marcadores e estereótipos de acordo com o tipo de avaliação que eles recebem socialmente. Os traços linguísticos com pouca força avaliativa são classificados como indicadores. Esses traços estão encaixados numa matriz social, mas não exibem nenhum padrão de alternância estilística. Os marcadores apresentam estratificação estilística e estratificação social, produzindo respostas regulares em testes de reação subjetiva. Os estereótipos são formas socialmente marcadas, rotuladas enfaticamente pela sociedade, apresentam determinada característica que serve para identificá-las.

Quando uma variante é mais evidente, mais perceptível para a comunidade e seus membros, esse traço linguístico pode ser alvo de comentário social, muitas vezes, julgamentos negativos que corroboram para a não aceitação social da variante, influenciando os processos de variação ou mudança linguísticas. As atitudes positivas ou negativas são baseadas na percepção e avaliação social dos traços linguísticos, levando em conta fatores políticos e culturais. 
Na seção seguinte, apresentamos os procedimentos metodológicos, descrevendo o processo de elaboração e de aplicação do questionário de atitudes linguísticas.

\section{Procedimentos metodológicos}

A análise da percepção e da avaliação social de estudantes a respeito da palatalização do /S/ em coda foi realizada a partir de um questionário de atitudes linguísticas. A partir dos pressupostos da Sociolinguística Variacionista (LABOV, 2008), adotando uma abordagem direta de julgamento metalinguístico, realizamos a gravação de questionário de atitudes com perguntas relacionadas a estímulos com a realização palatal do /S/ em coda. Realizamos a coleta de dados na Universidade Federal de Sergipe, Campus Prof. Alberto Carvalho, Itabaiana/SE, constituindo um corpus de 60 questionários de atitudes linguísticas.

As perguntas do questionário foram elaboradas visando captar a avaliação social que os universitários fazem da palatalização do /S/ em coda, considerando a percepção do fenômeno, as crenças relativas ao próprio uso linguístico, bem como da comunidade onde vivem, o julgamento da realização palatalizada e a relação que o falante estabelece entre o fenômeno e questões de ordem regional e/ou social, como região, escolaridade e preconceito linguístico.

Para captar a percepção da palatalização do /S/ em coda, utilizamos estímulos levando em conta

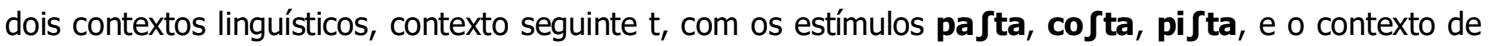
coda externa, com os estímulos lápi , ônibu , depoi . No contexto em que a coda silábica é seguida de uma consoante desvozeada [t], em posição interna, o /S/ pode ser realizado fonologicamente de maneira alveolar ou palatal, respectivamente: "paSta, pasta"; "coSta, cofta"; "piSta, pifta". O /S/ na posição de coda externa também apresenta a possibilidade de realização alveolar ou palatal, respectivamente: "lápiS, lápiS"; "ônibuS, ônibuS", "depoiS, depoi厅". A aplicação do teste foi realizada com a forma palatal dos estímulos em cada contexto, a fim de analisarmos a percepção e a avaliação da palatalização do /S/ nos dois contextos linguísticos.

Para cada contexto linguístico, foram realizadas seis perguntas de julgamento metalinguístico. Inicialmente, a partir da realização palatalizada dos estímulos, conforme questão 1 abaixo, perguntou-se se essa forma de falar era comum onde o informante mora, a fim de captar a percepção da realização palatal. A pergunta seguinte tinha o objetivo de mensurar as crenças dos universitários em relação ao próprio comportamento linguístico. A questão 3 relaciona-se ao julgamento do fenômeno. As três últimas perguntas estão relacionadas ao aspecto geográfico, à escolaridade e ao preconceito linguístico, visando analisar a relação que os estudantes fazem entre a palatalização do /S/ e fatores sociais.

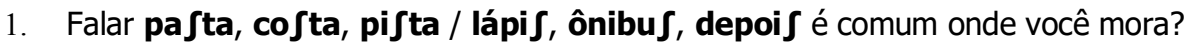

2. Você fala assim? Por quê?

3. O que você acha desse jeito de falar?

4. Você acha que esse jeito de falar é típico de algum lugar do Brasil? E aqui em Sergipe?

5. Você acha que esse modo de falar tem a ver com o nível de estudo da pessoa? Por quê?

6. Você acha que as pessoas que falam desse modo sofrem preconceito? Por quê? 
Na seção seguinte, apresentamos a percepção dos universitários do Campus Prof. Alberto Carvalho em relação à palatalização do /S/ em coda.

Atitudes linguísticas de universitários em relação à palatalização do /S/ em coda

Nesta seção, apresentamos os resultados e as discussões a respeito da percepção e avaliação de universitários em relação à palatalização do /S/ em coda. Primeiramente, apresentamos os resultados da percepção linguística do fenômeno. Em seguida, descrevemos as crenças dos universitários em relação ao uso da variante palatalizada. Depois, expomos os resultados obtidos quanto à avaliação social e a percepção dos fatores regionalidade, escolaridade e preconceito linguístico, respectivamente.

Para verificarmos a percepção linguística do fenômeno pelos universitários, fizemos a primeira pergunta sobre a questão do fenômeno ser ou não ser comum no lugar onde eles vivem, realizando o modo de falar palatalizado nas palavras selecionadas, conforme descrito na seção dos procedimentos metodológicos. Os resultados a respeito da percepção linguística dos universitários são apresentados no gráfico 1 , tendo em vista o contexto seguinte t e o contexto de coda externa.

Gráfico 1: Percepção linguística do fenômeno

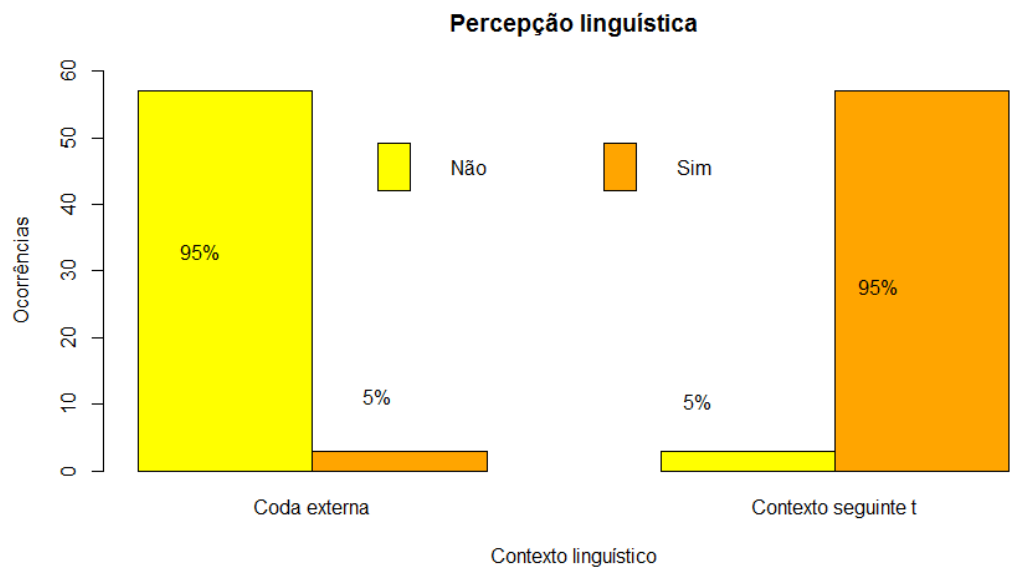

Fonte: Elaborado pelas autoras.

A partir do gráfico 1, tomando por base o contexto linguístico e a percepção do fenômeno, podemos perceber que os informantes consideraram a palatalização do /S/ com contexto seguinte t, do grupo de estímulos pa/ta, co/ta, pi/ta, como sendo comum no lugar em que eles moram, o que resultou, para esse contexto, um percentual de $95 \%$, ou seja, dos 60 testes aplicados, apenas 3 pessoas não consideraram comum para a região o modo de falar palatalizado. A palatalização do /S/ no contexto de coda externa, dos estímulos lápif, ônibu/, depoi/, não é considerada pelos universitários como comum para região onde vivem, com $95 \%$ de respostas não. Esse resultado mostra que os universitários percebem a realização palatal de forma distinta de acordo com o 
contexto linguístico.

A partir da pergunta "Você fala assim?", buscamos analisar a crença de uso dos universitários, isto é, se eles pensam que utilizam ou não a forma palatalizada do /S/ em coda. Podemos observar, no gráfico 2, as crenças dos universitários em relação à palatalização do /S/ em coda, considerando os dois contextos do questionário de atitudes.

Gráfico 2: Crenças em relação ao comportamento linguístico

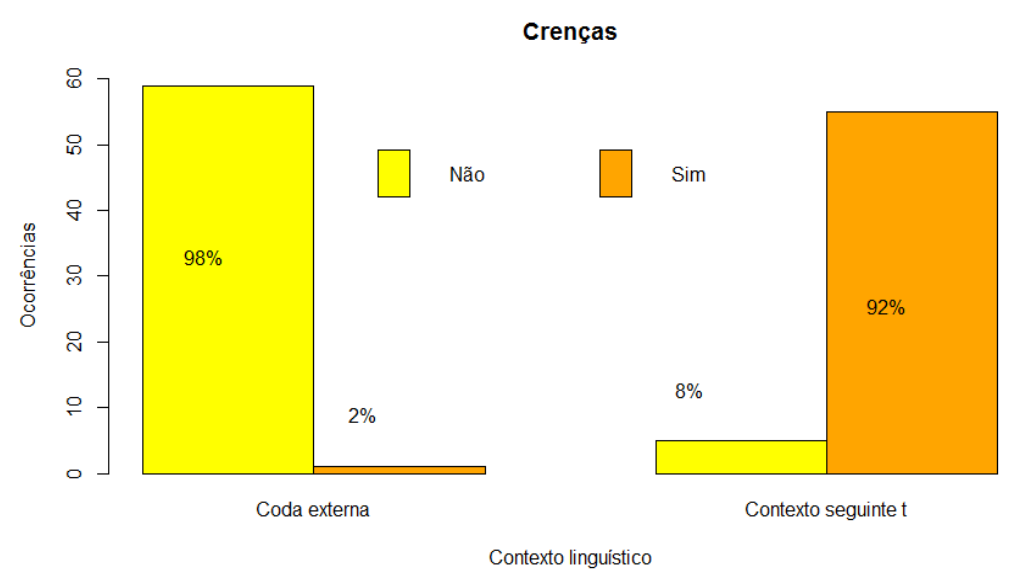

Fonte: Elaborado pelas autoras.

Ao analisarmos o gráfico 2, notamos que $92 \%$ das respostas dadas pelos informantes foram positivas para o uso linguístico da forma palatal do /S/ com contexto seguinte t. Ao contrário do contexto de coda externa, com $98 \%$ de negação do uso dessa forma linguística. Dentre os 60 testes aplicados, apenas um informante alegou falar a forma palatalizada nesse contexto. Quando questionado o porquê de os informantes não utilizarem o modo de falar reproduzido nos estímulos no contexto de coda externa, as respostas relacionaram essa realização a outras regiões, conforme exemplos em (1) e (2).

(1) "porque eu acho que a gente não tem muito contato com esse puxar... com esse S muito... é só mais pra quem vai pra região sudeste aí volta já com ele com esse sotaque puxado" (Alif).

(2) "porque também é um sotaque eu num... costumo falar assim eu falo do jeito que todo mundo fala aqui na região" (Bia-f).

No exemplo (1), o informante alega que não fala dessa forma por considerar que esse modo de falar seja da região Sudeste. $O$ falante também faz menção ao efeito do contato linguístico, afirmando que pessoas da região onde ele vive podem realizar esse comportamento quando viajam para a região onde falam dessa forma. Também relacionando a forma palatalizada de /S/ no contexto de coda externa ao fator regional, o informante, em (2), afirma não usar a forma palatal por ser um sotaque que não pertence a região dele. 
A partir da análise dos gráficos 1 e 2, relacionados à percepção e à crença do fenômeno da palatalização do $/ S /$ em coda, percebemos que, no contexto seguinte $t$, tanto a percepção quanto a crença dos universitários foram positivas. Ao contrário do contexto de coda externa, associado pelos informantes a outras regiões do país, negando o uso linguístico nesse contexto.

A partir dos julgamentos metalinguísticos dos universitários, captados a partir da pergunta "O que você acha desse jeito de falar?", analisamos a avaliação social do fenômeno, a fim de observarmos se há uma posição positiva ou negativa em relação à palatalização do $/ \mathrm{S} /$. Os resultados considerando os dois grupos de estímulos são apresentados em nuvens de palavras (cf. figuras 1 e 2), em que as palavras em destaque representam os julgamentos mais realizados pelos universitários.

Figura 1: Avaliação social da palatalização do /S/ com contexto seguinte t

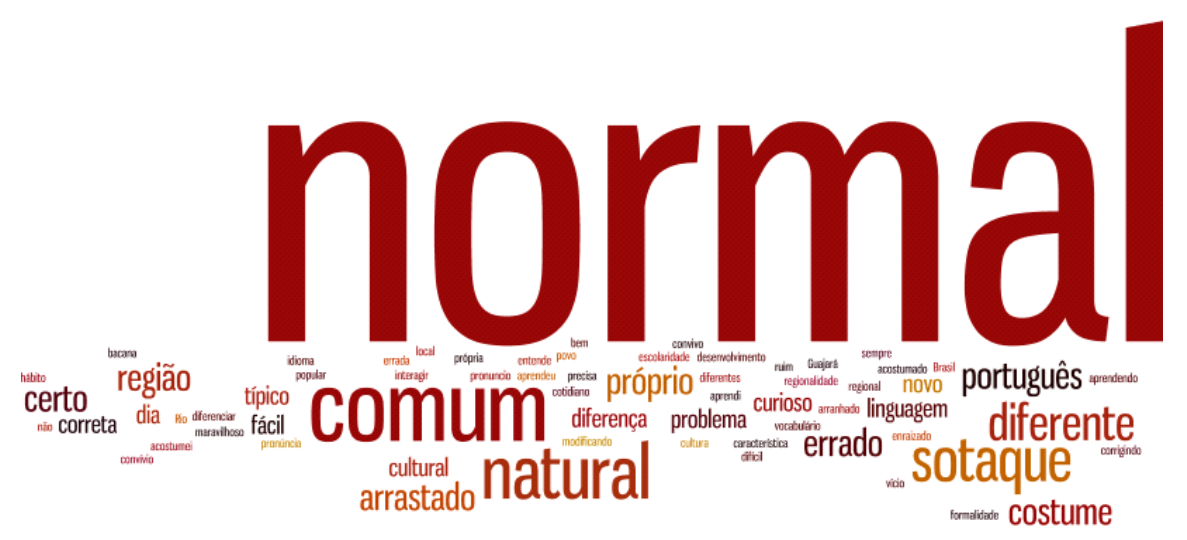

Fonte: elaborado pelas autoras.

A avaliação dos universitários em relação à palatalização do /S/ com contexto seguinte $t$, mais especificamente da realização palatal dos estímulos pa/ta, co/ta, pi/ta, foi bastante positiva. Podemos perceber, na figura 1, avaliações positivas desse contexto, considerando o modo de falar como algo "comum", "natural", ligado à "cultura" e ao "costume" das pessoas que moram na região, com destaque para o julgamento "normal". Em (3) e (4), apresentamos exemplos de respostas ao questionamento de julgamento metalinguístico em relação à palatalização com contexto seguinte t.

(3) "eh... é a forma que eu aprendi a falar pasta pista costa a pronúncia que eu pronuncio normal no meu dia a dia" (Gab-f).

(4) "eh... eu acho que é próprio da região né e é como se fosse uma própria característica do povo né tá muito atrelado também a cultura né por isso que a gente tem né em cada canto do Brasil as pessoas que falam eh... tem sotaque diferente sendo que só temos um idioma a gente fala de várias formas" (Wil-m).

Podemos perceber, nos exemplos citados, que os informantes avaliam positivamente o modo de falar palatalizado nesse contexto, já que o veem como algo normal, que está atrelado à cultura da região 
em que vivem. Observamos também que eles percebem a realização variável do /S/ em coda, relacionando-a ao sotaque.

A avaliação dos universitários em relação à palatalização do /S/ no contexto de coda externa, mais especificamente da realização palatal do $/ S /$ nas palavras lápi $\boldsymbol{S}$, ônibu $\boldsymbol{S}$, depoi $\boldsymbol{S}$, recebeu avaliação distinta da recebida pela palatalização do /S/ com contexto seguinte t. Podemos perceber, na figura 2, que o modo de falar foi avaliado negativamente pelos informantes, considerando-o "diferente", "estranho", "engraçado", "esquisito" ou "errado". Além de caracterizarem o fenômeno de forma negativa, também associaram-no à questão cultural, ao modo de falar adquirido no convívio com a comunidade, ao sotaque e à questão da regionalidade.

Figura 2: Avaliação social da palatalização do /S/ em contexto de coda externa.

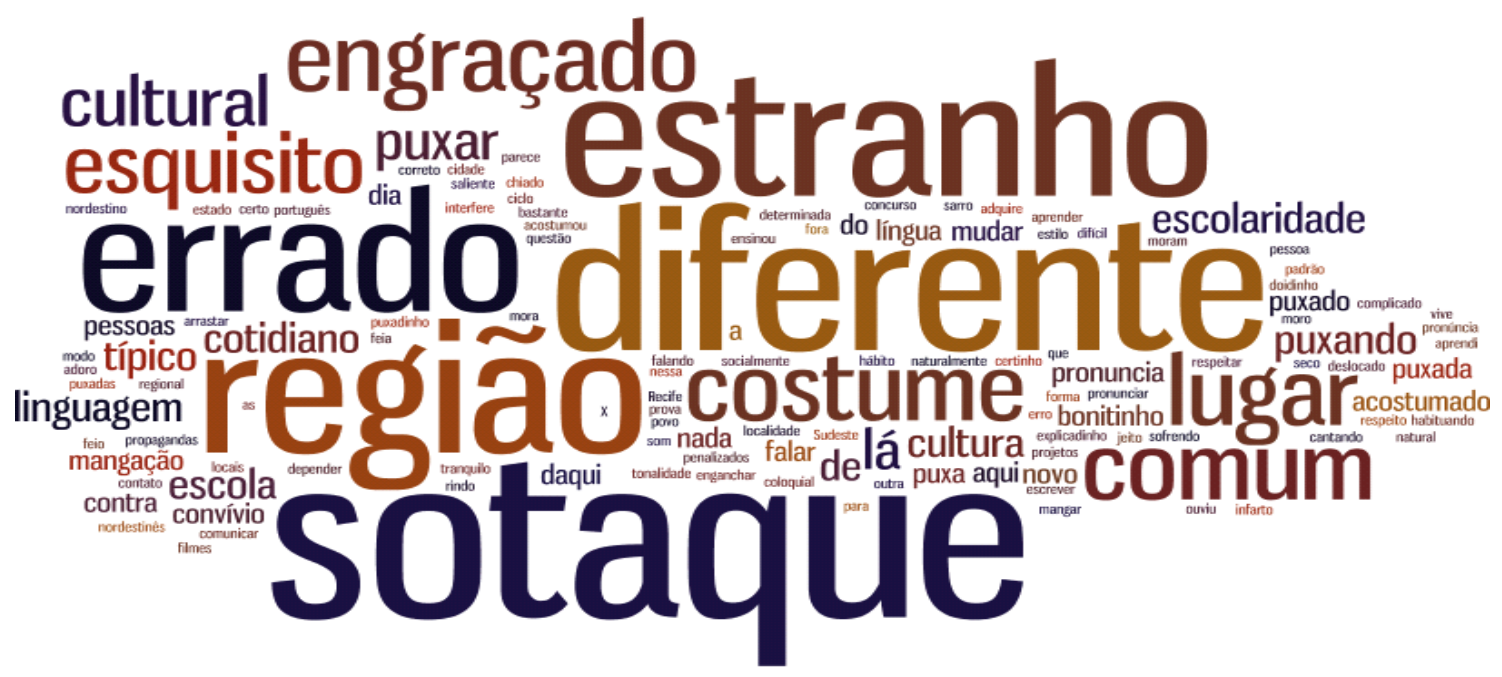

Fonte: elaborado pelas autoras.

Em (5) e (6), são apresentadas avaliações negativas em relação à palatalização do /S/ em contexto de coda externa. Os informantes avaliam o fenômeno negativamente, tachando-o como feio, errado e esquisito. Há também, em (6), a presença de julgamento metalinguístico de caráter normativo, avaliando o modo de falar como "fora do padrão".

(5) "eu acho feio" ((RISOS)) (Raq-f).

(6) "esquisito fora do padrão na verdade" (Tar-m).

Para verificarmos se a percepção dos universitários sobre o fenômeno da palatalização do /S/ em coda considera o fator regional, realizamos também as perguntas "Você acha que esse jeito de falar é típico de algum lugar do Brasil? E aqui em Sergipe?". Os resultados obtidos a partir da análise estão apresentados no gráfico 3. 
Gráfico 3: Percepção do fator regional

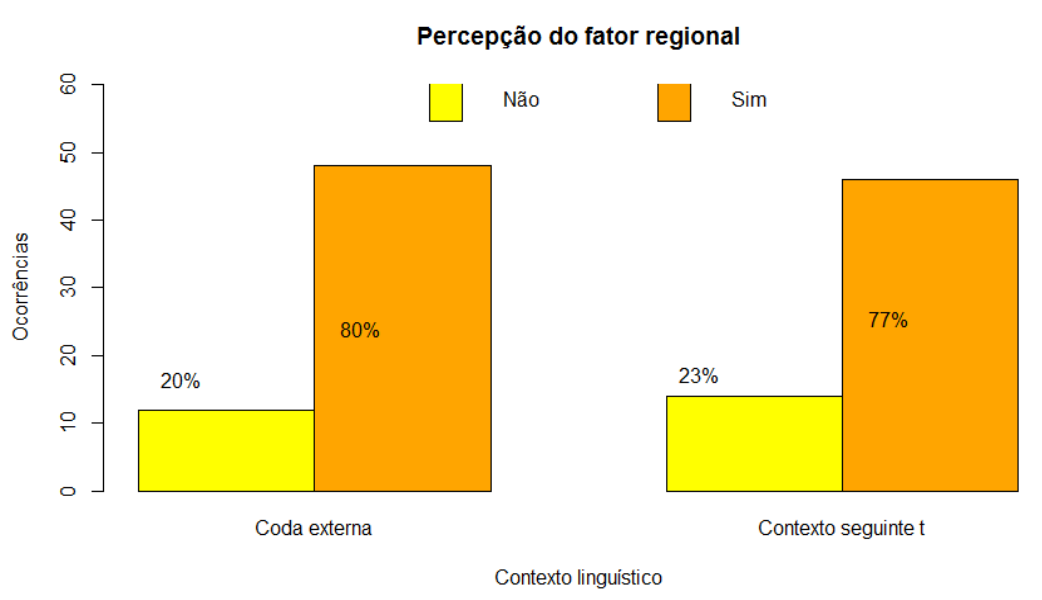

Fonte: Elaborado pelas autoras.

De acordo com o gráfico 3, percebemos que os informantes associaram o modo de falar palatalizado à questão regional, tanto no contexto seguinte t quanto no contexto de coda externa, com percentual de $77 \%$ e $80 \%$, respectivamente. Esse resultado indica que os universitários consideram a realização palatal do /S/ em coda como sendo algo que está ligado ao contexto geográfico, ao ambiente em que as pessoas vivem e comunicam-se entre si. Porém, embora os dois grupos de estímulos tenham sido relacionados ao fator regional, as regiões relacionadas a cada contexto linguístico são diferentes, conforme figuras 3 e 4 .

Figura 3: Percepção do fator regional em relação à palatalização de /S/ no contexto seguinte t

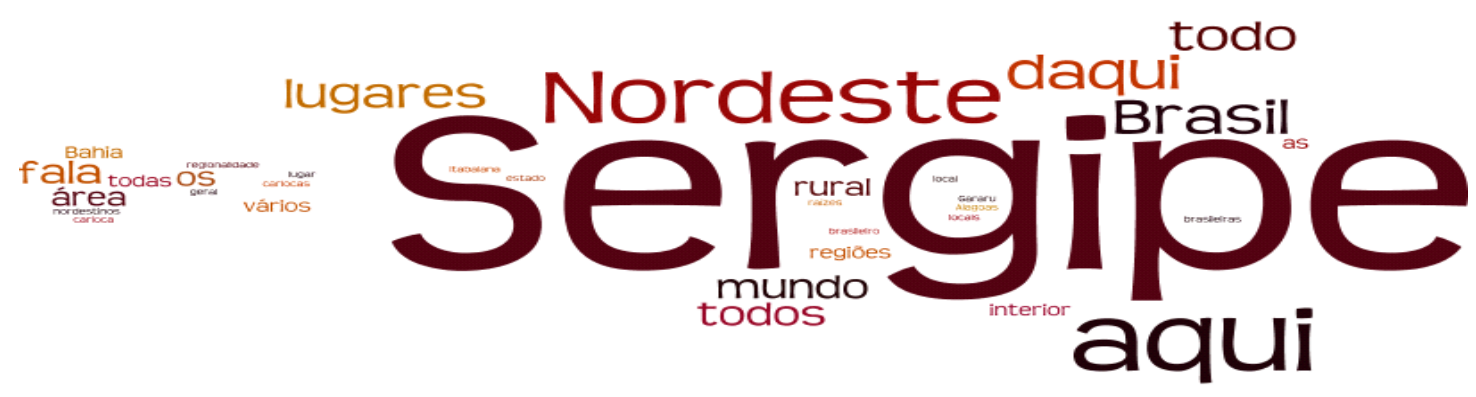

Fonte: elaborado pelas autoras.

Ao analisarmos a figura 3, levando em conta a percepção do fator regional em relação à palatalização de /S/ com contexto seguinte $t$, percebemos que os informantes correlacionaram o modo de falar, mais especificamente, à região Nordeste, considerando Sergipe como o estado típico para a presença do modo de falar palatalizado nesse contexto, conforme resposta transcrita em (7). 
(7) "bom acredito que pra minha região onde eu moro pra o meu estado é normal mais acredito que há variações pra o resto do Brasil" (Gab-m).

Em (7), o informante, além de afirmar que o modo de falar apresentado nos estímulos é normal para a região dele, também demonstra consciência da diversidade linguística do país ao considerar que, em outras regiões, possa haver variações. No que concerne à palatalização de /S/ no contexto de coda externa, os informantes relacionaram o modo de falar palatalizado às pessoas que moram em outro estado, mais especificamente em outra região, como a região Sudeste, sobretudo no estado do Rio de Janeiro, conforme figura 4.

Figura 4: Percepção do fator regional em relação à palatalização de /S/ no contexto de coda externa

\section{Pernambuco

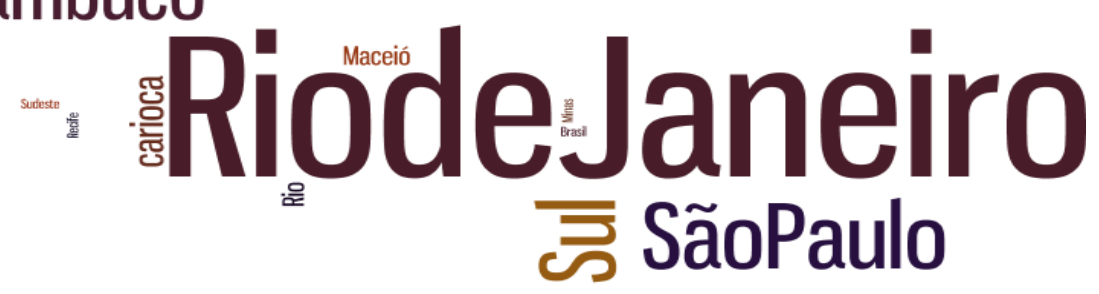

Fonte: elaborado pelas autoras.

Observamos, na imagem, além do destaque da região Sudeste, a relação do modo de falar palatalizado representado nos estímulos à região Nordeste, Pernambuco e Maceió, e à região Sul. No exemplo em (8), o informante relaciona a forma palatal presente nos estímulos ao Rio de Janeiro, além de afirmar que essa forma de falar não é comum de Sergipe, mas acredita que possa haver pessoas em Sergipe que falem dessa forma caso a pessoa tenha passado a morar no estado, mas seja do Rio de Janeiro.

(8) "INF: sim do Rio de Janeiro ((RISOS))

ENT: e aqui em Sergipe?

INF: não só algumas pessoas que vêm de lá agora" (Fer-m).

A partir da pergunta "Você acha que esse modo de falar tem a ver com o nível de estudo da pessoa? Por quê?", buscamos analisar se os informantes consideram o modo de falar palatalizado relacionado ao nível de escolaridade do falante. No gráfico 4, apresentamos os resultados para a percepção da relação entre a forma palatalizada e a escolaridade, considerando a coda com contexto seguinte t e o contexto de coda externa. 
Gráfico 4: Percepção do fator escolaridade

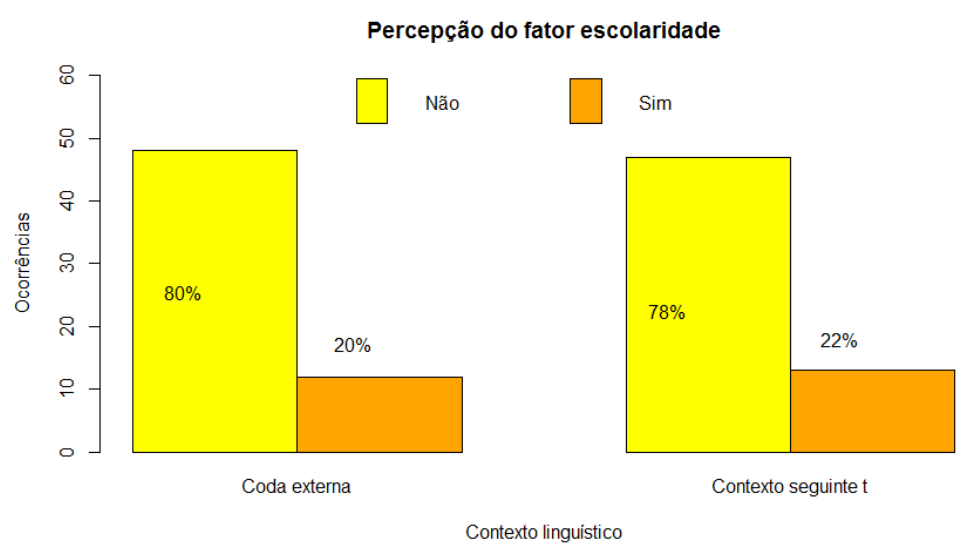

Fonte: Elaborado pelas autoras.

Ao analisarmos o gráfico 4, de acordo com a percepção do fator escolaridade, constatamos que, tanto no contexto seguinte $t$ quanto no contexto de coda externa, os informantes afirmam que a forma de falar palatal não tem a ver com o nível de estudo da pessoa, com percentual de $78 \%$ e $80 \%$, respectivamente. Esse resultado mostra, no que diz respeito à escolaridade, que a percepção dos universitários em relação à palatalização do $/ \mathrm{S} /$, tanto com o contexto seguinte $\mathrm{t}$, quanto em contexto de coda externa, apresenta valor regional, correlacionando o fenômeno às noções de sotaque e cultura, dissociando-o do nível de estudo do falante. Em (9), o informante, referindo-se aos estímulos com /S/ em coda seguido de $t$, relaciona esse modo de falar aos costumes adquiridos em uma comunidade. No que se refere à palatalização do /S/ no contexto de coda externa, o informante, em (10), associa o fenômeno linguístico à noção de sotaque, defendendo que não há relação com a escolaridade do falante.

(9) "não não e sim com ... eh... eu acho que não tem não não tem não porque isso é devido ah... as raízes né de onde ele mora ali... acaba o pessoal acaba adquirindo os costumes do povo dali daquela região então não tem nada a ver com escolaridade não" (Jos-m).

(10) "não ... eu acho que é o sotaque mesmo de onde a pessoa mora" (Raq-f).

Consideramos também, no questionário de atitudes, a questão do preconceito linguístico, com a seguinte pergunta "Você acha que as pessoas que falam desse modo sofrem preconceito? Por quê?", a fim de verificarmos se os informantes veem o fenômeno da palatalização do /S/ em coda como alvo de preconceito ou se os próprios informantes exercem preconceito sobre o fenômeno linguístico. Observamos os resultados obtidos no gráfico 5 . 
Gráfico 5: Percepção do preconceito linguístico.

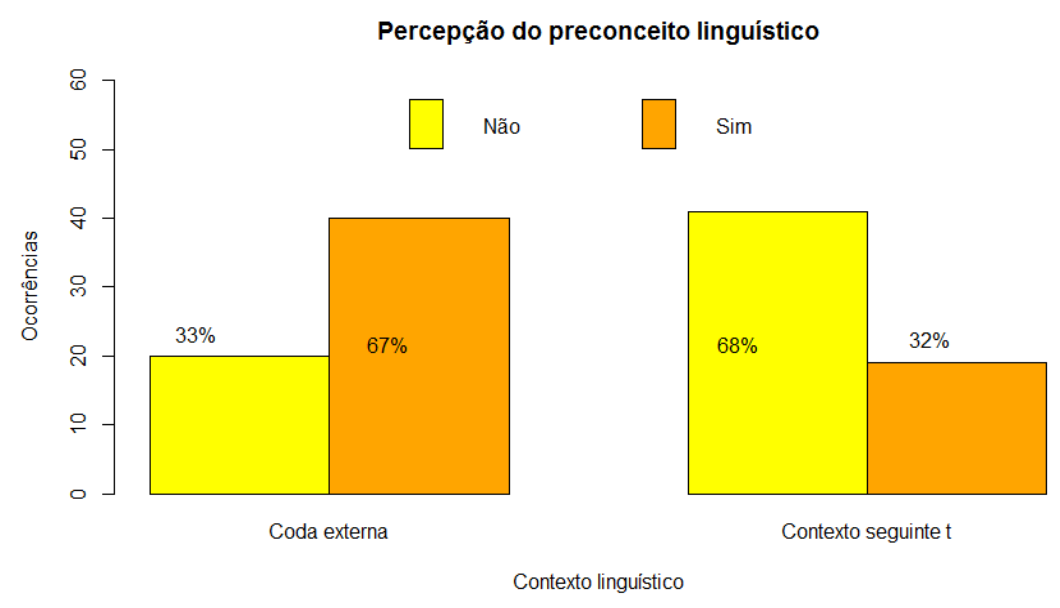

Fonte: Elaborado pelas autoras.

Ao examinarmos o gráfico 5 , levando em conta a percepção do preconceito linguístico, notamos que, tanto no contexto seguinte $t$ quanto no contexto de coda externa, os informantes alegam que as pessoas que falam a forma palatalizada são alvo de algum tipo de julgamento. Porém, na percepção dos universitários da UFS/Itabaiana, a palatalização no contexto de coda externa tende a ser mais alvo de preconceito, com percentual de $67 \%$. Em (11), referindo-se aos estímulos com palatalização do /S/ em coda externa, o informante afirma que sempre há preconceito em relação às formas diferentes de falar, pois há estranhamento, o que gera críticas.

(11) "sim acredito que sim sempre há um preconceitozinho por trás das coisas porque quando a pessoa não é acostumada a ouvir e aí acha diferente então outras criticam outras julgam outras riem" (Ale-f).

A partir da análise das atitudes linguísticas dos universitários da Universidade Federal de Sergipe, Campus Prof. Alberto Carvalho, Itabaiana/SE, percebemos que o fenômeno da palatalização do /S/ em coda recebeu valoração social distinta em cada contexto linguístico. Evidenciamos uma aceitação maior da palatalização no contexto seguinte $t$ do que no contexto de coda externa, obtendo uma avaliação mais positiva no primeiro contexto do que no segundo. Os informantes associaram a palatalização do /S/ em coda à questão regional em ambos contextos, independentemente do nível de escolaridade. Em relação à percepção do preconceito linguístico, observamos que, de acordo com a percepção dos universitários, o contexto de coda externa é mais propício a ser alvo de julgamento negativo do que o contexto seguinte $t$. O quadro abaixo apresenta uma sumarização da percepção dos universitários em função do contexto linguístico. 
Quadro 1: Percepção da palatalização do /S/ em função do contexto linguístico

\begin{tabular}{|c|c|c|}
\hline & Contexto seguinte t & Coda externa \\
\hline Percepção & É comum na região & Não é comum na região \\
\hline Crença & Usa & Estranho usa \\
\hline Avaliação social & Normal & Rio de Janeiro \\
\hline Região & Sergipe & Não está relacionado \\
\hline Escolaridade & Não está relacionado & Alvo de preconceito \\
\hline Preconceito & Não é alvo de preconceito & \\
\hline
\end{tabular}

Fonte: Elaborado pelas autoras.

Ao observarmos o quadro 1 , constatamos que a palatalização do /S/ em coda foi avaliada pelos informantes de forma diferente de acordo com o contexto linguístico. Os resultados mostram que os universitários acreditam usar a forma palatal no contexto seguinte $t$, considerando-a normal e comum em Sergipe. Ao contrário do contexto de coda externa, em que os resultados mostram que os universitários negam o uso da forma palatal nesse contexto, além de julgá-la estranha e comum do Rio de Janeiro. A palatalização do /S/ em coda não foi relacionada à escolaridade, mas à questão regional. Em relação ao preconceito, constatamos que, no contexto de coda externa, a palatalização do /S/ tende a ser avaliada mais negativamente do que no contexto seguinte $t$. Os resultados evidenciam que a percepção da palatalização pelos universitários é sensível ao contexto linguístico.

\section{Considerações finais}

A partir do estudo sobre a percepção e a avaliação da palatalização do /S/ em coda, na Universidade Federal de Sergipe, Campus Prof. Alberto Carvalho, pudemos observar que os informantes mudam os seus julgamentos de acordo com o contexto linguístico em que a coda ocorre. A percepção e a crença linguísticas foram positivas no contexto seguinte $t$, pois os universitários afirmaram que tanto eles quanto a comunidade onde vivem usam essa variante. Em relação à avaliação social, constatamos que a palatalização do /S/ em coda foi avaliada mais positivamente no contexto seguinte $t$, considerando-a normal e comum, ligada à cultura e ao costume das pessoas da região. No contexto de coda externa, percebemos uma avaliação mais negativa, considerando a forma palatal feia, estranha e errada, além de caracterizá-la como pertencente sobretudo à região Sudeste.

Em relação ao fator regional, tanto no contexto seguinte t quanto no contexto de coda externa, os informantes relacionaram o fenômeno da palatalização do /S/ à questão da regionalidade. O primeiro 
contexto foi considerado típico da região Nordeste, sobretudo do estado de Sergipe; já o segundo, típico principalmente da região Sudeste, com destaque para o estado do Rio de Janeiro. Tratando-se do fator escolaridade, constatamos que, em ambos os contextos, o modo de falar palatalizado não tem a ver com o nível de estudo da pessoa, mas está atrelado, de fato, à questão da regionalidade. Por fim, a respeito do preconceito linguístico, o contexto de coda externa é mais propício ao julgamento pelas pessoas, obtendo uma avaliação mais negativa, ao contrário do contexto seguinte $t$.

Os resultados evidenciam que a palatalização do /S/ em coda está no nível da consciência dos universitários da Universidade Federal de Sergipe, Campus Prof. Alberto Carvalho, pois a percepção dos estudantes apresenta consistência ao avaliar os contextos linguísticos com valores sociais distintos. Os universitários consideram a forma palatalizada de $/ \mathrm{S} /$ no contexto seguinte t como comum à comunidade e ao próprio uso linguístico, avaliando-a, portanto, positivamente. Por outro lado, os universitários afirmam não usar o /S/ palatal no contexto de coda externa, não o considerando comum na região onde vivem, avaliando, dessa forma, esse uso de forma negativa.

\section{Referências}

ALKMIM, T. M. Sociolinguística. Parte I. In: MUSSALIM, F.; BENTES, A. C. (orgs.). Introdução à linguística: domínios e fronteiras. São Paulo: Cortez, 2001. p. 21-47.

CAMACHO, R. G. Sociolinguística. Parte II. In: MUSSALIM, F.; BENTES, A. C. (orgs.) Introdução à linguística: domínios e fronteiras. São Paulo: Cortez, 2001. p. 49-75.

FARACO, C. A. Português do Brasil: a construção da norma culta e as práticas de ensino. Olimpíadas LP. 2012. Disponível em: <https://www.youtube.com/watch?v=CUKfzAeGNrE> Acesso em: 26 ago. 2018.

FREITAG, R. M. K. et al. Avaliação e variação linguística: estereótipos, marcadores e indicadores em uma comunidade escolar. In: FREITAG, R. M. K.; SEVERO, C. G.; GÖRSKI, E. M. (orgs.). Sociolinguística e política linguística: olhares contemporâneos. São Paulo, Blucher, 2016. p. 139-159.

LABOV, W. Padrões Sociolinguísticos. Trad. BAGNO, M.; SCHERRE, M.; CARDOSO, C. $1^{\text {a }}$ ed. São Paulo: Parábola, 2008. 392p.

OUSHIRO, L. Identidade na pluralidade: avaliação, produção e percepção linguística na cidade de São Paulo. Tese (Doutorado em Linguística). 2015. 394f. - Faculdade de Filosofia, Letras e Ciências Humanas, Universidade Federal de São Paulo. São Paulo, 2015.

SILVA, T. C. Fonética e Fonologia do Português. roteiro de estudos e guia de exercícios. 7 a ed. São Paulo: Contexto, 2003. 186p.

WEINREICH, U.; LABOV, W.; HERZOG, M. Fundamentos empíricos para uma teoria da mudança linguística. Trad. BAGNO, M. $1^{a}$ ed. São Paulo: Parábola, 2006. 153p. 